SPECIAL SECTION

\title{
Premodern Historical Systems: The Rise and Fall of States and Empires
}

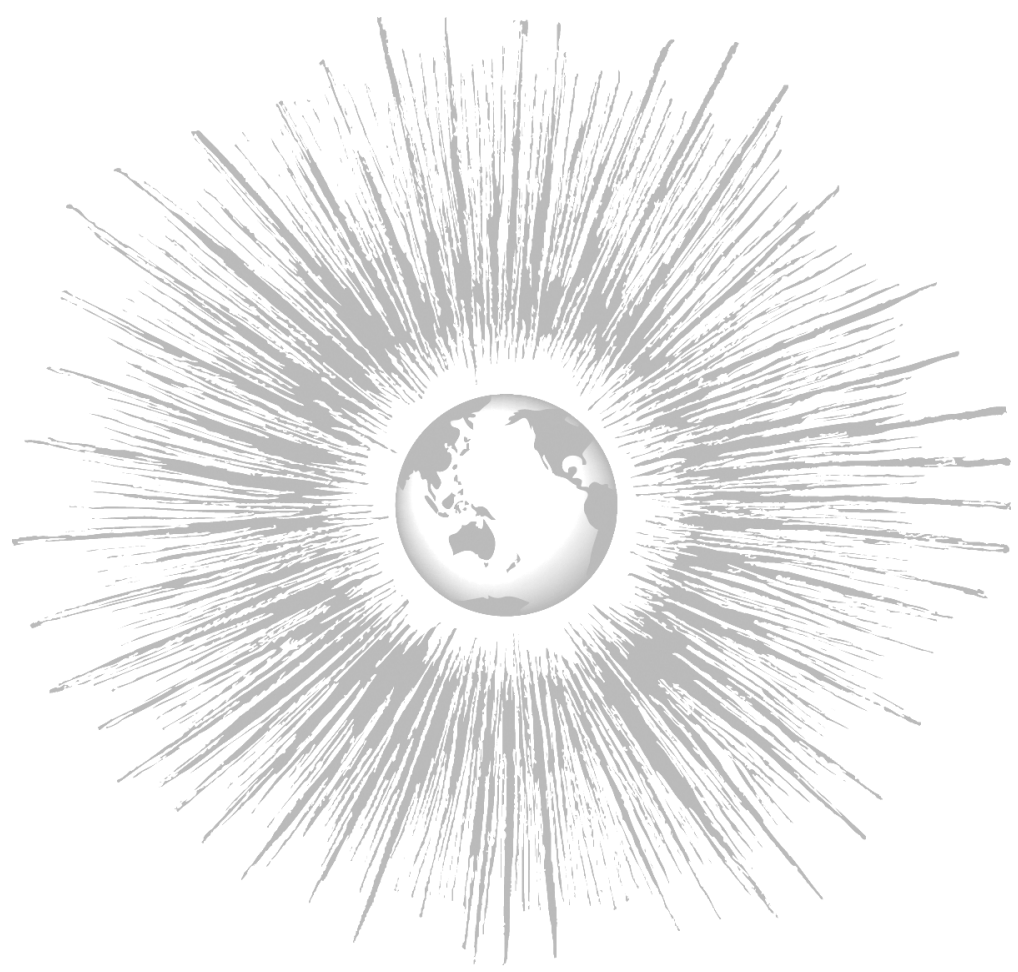

By Christopher Chase-Dunn Co-Editor

Lere are three studies of the phe1 nomenon of rise and fall in premodern historical systems. In the modern world-system an analogous process takes the form of the rise and fall of hegemonic core powers, and the arena of contention became global in scope during the $19^{\text {th }}$ century (C.E.). The studies here are of three different and largely separate regional world-systems during different time periods. All three focus on state formation, empire building and collapse.

Thompson's study is one of the first to systematically test for possible causes of the sequence of increasing and then decreasing societal complexity and political centralization/decentralization in Bronze Age Mesopotamia. He employs the methods of bivariate and multivari ate time series logit analysis to examine the temporal and causal relationships between urbanization, economic disorder, trade disruptions, climate change and incursions by peripheral peoples.

Wilkinson's study is one of a series in which he reads standard histories in order to code the power configuration of interstate systems at ten-year intervals. "Power configuration" codes the degree of centralization of state systems as seven ordinal categories, ranging from total empire to "non-polarity" (no great powers, many small independent states). Wilkinson's focus in this study is the "Central" system from 1500 to 700 B.C.E. The Central system was formed near the beginning of this time period by merger of the formerly separate Egyptian and Mesopotamian state systems. ${ }^{1}$ Wilkinson discusses the results of his prodigious coding endeavor in historical and comparative perspective, reflecting on some of the explanations for the transitions in power configuration that he finds.

Kea's study uses recent archaeological evidence from West Africa to examine the emergence of states and urbanized regions before and during the African Iron Age. His study shows patterns of rise and fall, and shifting centers of power within the West African system, and he convincingly makes the case that this regional system played a generative ideological and financial role as it expanded and merged with the Mediterranean system.

1. These regions had been linked by prestige goods exchanges since before 3000 вСЕ.

JOURNAL OF WORLD-SYSTEMS RESEARCH, X, 3, FALL 2004, 6 II http://jwsr.ucr.edu/ 